\title{
Recovery of Dissolved Metals from Beneficiation Wastewater by Electrochemical Oxidation
}

\author{
Shupeng Liu ${ }^{1, *}$, Xiaowei Zhang ${ }^{1}$, Fang Wei ${ }^{2}$ \\ ${ }^{1}$ HeiBei GEO University (school of Gemology and Materials Technology), No.136, Huaian East Rd, \\ Shijiazhuang, 050030, China, \\ ${ }^{2}$ Hydrogeology and Engineering Geology Survey Institute, Geology and Mineral Exploration Bureau \\ of Hebei Province, No. 131 Huaizhong Rd, Shijiazhuang, 050030 China \\ *E-mail: shupengliu_hgu@163.com
}

doi: $10.20964 / 2016.08 .69$

Received: 23 May 2016 / Accepted: 19 June 2016 / Published: 7 July 2016

\begin{abstract}
Beneficiation wastewater, grew out of the mine industry, has made a very wide range of pollution owing to the large amount of metals such as $\mathrm{Fe}, \mathrm{Ni}$, and $\mathrm{Mn}$ contained in it. The materials for selectively recover the including metals in beneficiation wastewater was highly demanded. In our work, an electrochemical method was explored to produce the highly required materials (neutralizing agents). In the direct oxidation reaction, the graphite electrode demonstrated the best performance with highest rate compared with BDD electrode and titanium electrode. Salt bridge was used as a connecting medium owing to its lowest $\mathrm{Fe}$ ions loss resulted from the slower migration rate of Fe into the catholyte. The catholyte produced by electrochemical methods has been applied as a neutralizing agent due to the high $\mathrm{pH}$ value. The potential of the usage of catholyte in selective recovery of dissolved metals in beneficiation wastewater has verified the successful use of electrochemical methods.
\end{abstract}

Keywords: Beneficiation wastewater; Electro-oxidation; Recovery; Fe; Precipitation

\section{FULLTEXT}

(C) 2016 The Authors. Published by ESG (www.electrochemsci.org). This article is an open access article distributed under the terms and conditions of the Creative Commons Attribution license (http://creativecommons.org/licenses/by/4.0/). 